\title{
Echocardiographic evaluation of mitral durability following valve repair in rheumatic mitral valve disease: Impact of Maze procedure
}

\author{
Gwan Sic Kim, Chee Hoon Lee, Joon Bum Kim, Sung-Ho Jung, Suk Jung Choo, Cheol Hyun Chung, and
} Jae Won Lee, MD

Objective: The data on echocardiographic evaluation of mitral durability after rheumatic mitral repair is scarce.

Methods: A total of 193 patients (mean age, $39.4 \pm 12.8$ years; 154 females) who underwent mitral valve repair for rheumatic valve disease from 1997 to 2010 were included in the study. A Maze operation was performed in $90.3 \%(\mathrm{n}=102)$ of the patients with atrial fibrillation $(\mathrm{n}=113)$. Survival, valve-related complications, and echocardiographic data were evaluated.

Results: Mitral regurgitation was the predominant disease in $75.6 \%$ of patients $(n=146)$. There was one early death $(0.5 \%)$. During the mean follow-up period of $76.7 \pm 45.6$ months, there were 9 late deaths and 5 mitral reoperations. Valve-related, event-free survival at 10 years was $85.5 \% \pm 3.3 \%$. In serial postoperative echocardiographic evaluations (mean follow-up duration, $53.7 \pm 43.5$ months), 40 patients showed either mitral regurgitation ( $>$ mild; $\mathrm{n}=31$ ) or mitral stenosis (mitral valve area $\leq 1.5 \mathrm{~cm}^{2} ; \mathrm{n}=9$ ). At 10 years, $66.4 \% \pm 5.4 \%$ of the patients did not have moderate to severe mitral dysfunction. By multivariate analysis, no Maze operation for atrial fibrillation was an independent predictor of mitral dysfunctions (hazard ratio, 3.72; 95\% confidence interval, $1.47-9.42 ; P=.005$ ), whereas the presence of hypertension had borderline significance (hazard ratio, $3.15 ; 95 \%$ confidence interval, $0.96-10.38 ; P=.059$ ).

Conclusions: Although rheumatic mitral repair showed excellent long-term clinical outcomes, a significant proportion of patients experienced moderate to severe mitral dysfunctions postoperatively. Atrial fibrillation without a Maze procedure increased significantly the risks of mitral dysfunctions and adverse outcomes. Therefore, routine performance of a Maze procedure is warranted in the presence of atrial fibrillation whenever possible. (J Thorac Cardiovasc Surg 2014;147:247-53)

Rheumatic mitral valve (MV) disease has a complex pathology that affects each level of the annulus, leaflet, and subvalvular apparatus, making it necessary to perform comprehensive repairs for each lesion in individual patients. ${ }^{1}$ With the development of mitral reconstructive techniques during the past few decades, ${ }^{2-5}$ several studies have demonstrated that MV repair is superior, in terms of increasing survival and decreasing valve-related events, to valve replacement for patients with degenerative mitral disease. $^{6-13}$

However, the long-term durability of rheumatic mitral repair remains questionable because rheumatic MV disease is a progressive lesion and there is the possibility of relapse even after successful repair. Previous studies have reported the durability of mitral repair based on the rate of reoperation. ${ }^{7,8}$ However, patients who experience

\footnotetext{
From the Department of Thoracic and Cardiovascular Surgery, Asan Medical Center, University of Ulsan College of Medicine, Seoul, Republic of Korea.

Disclosures: Authors have nothing to disclose with regard to commercial support.

Received for publication May 7, 2012; revisions received Sept 14, 2012; accepted for publication Oct 2, 2012; available ahead of print Nov 22, 2012.

Address for reprints: Jae Won Lee, MD, Department of Thoracic and Cardiovascular

Surgery, University of Ulsan College of Medicine, 88, Olympic-ro 43-gil, Songpa-

gu, Seoul, 138-736, Republic of Korea (E-mail: jwlee@amc.seoul.kr).

$0022-5223 / \$ 36.00$

Copyright (C) 2014 by The American Association for Thoracic Surgery

http://dx.doi.org/10.1016/j.jtcvs.2012.10.007
}

significant MV dysfunctions do not necessarily undergo valve reoperation, so any assessment of MV durability based only on reoperation would likely underestimate the rate of overall MV dysfunction. Although there are a few reports of MV dysfunctions after mitral repair based on echocardiographic evaluations, these studies focused only on recurrent mitral regurgitation (>grade 2) without consideration of mitral stenosis. ${ }^{5,14}$ Therefore, a quantitative evaluation of echocardiographic evaluations of MV function following valve repair that considers both mitral stenosis and mitral regurgitation is important.

Therefore, we sought to evaluate the long-term results of MV repair in patients with rheumatic MV disease. We also sought to determine the risk factors associated with the outcomes, especially MV dysfunctions that take into account both mitral stenosis and regurgitation.

\section{METHODS \\ Patients}

From January 1997 to June 2010, a total of 1699 patients underwent MV surgery for rheumatic mitral disease at Asan Medical Center, Seoul, South Korea. Of these patients, 378 underwent mitral repair. Patients with associated valve lesions, coronary artery diseases, diseases of the aorta, or pericardial diseases were excluded. Patients with a previous cardiac surgery were also excluded. However, patients who had associated incidental coronary lesions (ie, 1-vessel disease) or had undergone concomitant tricuspid repair were not excluded. Based on these guidelines, 193 patients who 


$$
\begin{aligned}
& \text { Abbreviations and Acronyms } \\
& \text { AF }=\text { atrial fibrillation } \\
& \text { CI }=\text { confidence interval } \\
& \mathrm{HR}=\text { hazard ratio } \\
& \mathrm{MV}=\text { mitral valve }
\end{aligned}
$$

underwent valve repair for rheumatic mitral disease were enrolled in this study. This study was approved by our institutional review board, which waived the requirement for informed patient consent based on the retrospective nature of the study.

\section{Surgical Procedures}

A median sternotomy approach was used for most patients (124/193, $64.2 \%$ ), and a minimally invasive approach with either the AESOP 3000 system (Automated Endoscope System for Optimal Positioning; Computer Motion, Inc, Santa Barbara, Calif) or the da Vinci system (Intuitive Surgical, Inc, Sunnyvale, Calif) was used for the more recent patients (69/193, $35.8 \%$ ). Conventional ascending aorta and bicaval cannulations were used for the sternotomy approach, and the minimally invasive approach involved peripheral cannulations through the right internal jugular vein, right femoral vein, and right femoral artery. Moderately hypothermic cardiopulmonary bypass was used, and myocardial protection was achieved with cold or tepid blood cardioplegia. After aortic crossclamping, a longitudinal right-sided left atriotomy was the conventional approach. Mitral valve repairs were performed according to the pathology of each level of the annulus, leaflet, and subvalvular apparatus, as described previously. ${ }^{9}$ Details of the MV repair techniques are summarized in Table 1. The Maze procedure was performed using either a classic cut-and-sew Cox-Maze III $(\mathrm{n}=11)$ or a modified Cox-Maze III procedure $(n=91$; cryoablation in 73 , microwave in 18). Specifically, during the minimally invasive surgery using either the AESOP or the da Vinci system, we performed cryoablation using a flexible probe (SurgiFrost; Medtronic, Minneapolis, Minn) via a right anterolateral minithoracotomy that ranged from 4 to $6 \mathrm{~cm}$. The lesion sets for the modified Cox-Maze III procedure have been described previously. ${ }^{15,16}$ The surgery was performed by the same surgeon.

\section{Follow-up}

Follow-up patient data were obtained from hospital records, clinical visits, and telephone interviews through June 2011. Data on vital status and date of death were obtained from the Korean national registry of vital statistics. Follow-up transthoracic echocardiographic evaluations were generally performed at 6-month intervals during the first year and every 2 years thereafter. Postoperatively, rhythms in patients were monitored daily using standard 12-channel surface electrocardiography. Follow-up electrocardiograms were performed at 3- to 6-month intervals during the first 2 years and every year thereafter. An episode of atrial fibrillation (AF), atrial tachycardia, or atrial flutter beyond the initial blanking period of 3 months was defined as a late AF event if it had a duration of $\geq 30 \mathrm{sec}$ onds by monitoring. Early mortality was defined as death within 30 days of surgery. Deaths were classified as cardiac or noncardiac on the basis of medical records. The definition of valve-related events was based on the guidelines for reporting mortality and morbidity after cardiac valve interventions. ${ }^{17}$

\section{Echocardiography}

Two-dimensional and Doppler echocardiographic examinations were performed in all patients using either a Hewlett-Packard Sonos 2500 or 5500 imaging system equipped with a $2.5-\mathrm{MHz}$ transducer (Hewlett-Packard, Andover, Mass). Preoperative echocardiography was performed in all patients $<2$ months prior to surgery. Mitral regurgitation was graded as either moderate $\left(0.2 \mathrm{~cm}^{2} \leq\right.$ effective regurgitant orifice area $\left.<0.4 \mathrm{~cm}^{2}\right)$ or severe (effective regurgitant orifice area $\geq 0.4 \mathrm{~cm}^{2}$ ). Mitral valve areas were estimated using the pressure half-time method. Significant pulmonary hypertension was defined as a tricuspid regurgitation peak velocity $>3.4 /$ $\mathrm{msec}$, equal to a pulmonary artery pressure $>50 \mathrm{~mm} \mathrm{Hg}$. Postoperative significant MV dysfunctions were defined as follows: (1) mitral regurgitation $>$ mild or (2) mitral stenosis defined by an MV area $\leq 1.5 \mathrm{~cm}^{2}$.

\section{Statistical Analysis}

Categoric variables are presented as frequencies and percentages, and continuous variables are expressed as means \pm SD or as medians and ranges. Kaplan-Meier curves were used to delineate overall survival; valve-related, event-free survival; and freedom from mitral dysfunction. Stratified survival curves were plotted to determine unadjusted differences for variables of interest (log-rank test). For multivariate analyses, the Cox proportional hazards model was used to determine the association of baseline characteristics with time to major adverse events (death- or valverelated complications) or MV dysfunction. Prespecified covariates (Table 1 and Table 2) and the presence of postoperative AF were included in this analysis. Variables with a probability value $<0.20$ in univariate analyses were candidates for analyses with the multivariate Cox proportional hazards model. Results were expressed as hazard ratios (HRs) with $95 \%$ confidence intervals $(\mathrm{CI}) . P$ values $<.05$ were considered significant. For further verification of the results of Cox regression analysis, the model was validated in 1000 bootstrap samples. SPSS version 18.0 (SPSS, Inc, Chicago, Ill) was used for all statistical analyses.

\section{RESULTS \\ Baseline Characteristics}

The mean age of patients at surgery was $39.4 \pm 12.8$ years, and $79.8 \%(n=154)$ were female. Forty-two percent of patients $(\mathrm{n}=81)$ were categorized as New York Heart Association functional class III or IV, and mitral regurgitation was the predominant disease in $75.6 \%$ of patients $(\mathrm{n}=146)$. A Maze operation was performed concomitantly with MV repair in $90.3 \%(\mathrm{n}=102)$ of patients with $\mathrm{AF}$ $(\mathrm{n}=113$; Table 2).

\section{Early Outcomes}

There was 1 early death $(0.5 \%)$. This patient died of unknown causes 30 days after discharge. There were 19 cases of early postoperative complications, including postoperative bleeding in 9 patients $(4.7 \%)$, pericardial effusion in 2 patients $(1.0 \%)$, sick sinus syndrome or complete atrioventricular block in 3 patients $(1.6 \%)$, and wound problems in 5 patients $(2.6 \%)$.

\section{Late Outcomes}

Clinical follow-up was $99 \%(\mathrm{n}=191)$ with a mean follow-up duration of $76.7 \pm 45.6$ months. There were 9 late deaths, of which 4 were patients who died of a cardiovascular cause. The causes of cardiovascular-related deaths included unknown origin in 2 patients, congestive heart failure in 1 patient, and a pseudo-aneurysm rupture of the ascending aorta 233 days after the initial surgery in 1 patient. Noncardiovascular causes of death were malignancy in 4 patients and meningitis in 1 patient. Overall, 
TABLE 1. Surgical techniques

\begin{tabular}{lc}
\hline \multicolumn{1}{c}{ Technique } & No. of cases $(\%)$ \\
\hline No. of patients & 193 \\
Surgical approach & \\
Median sternotomy & $124(64.2)$ \\
$\quad$ Minimally invasive approach & $69(35.8)$ \\
Mitral valve repair & \\
Annuloplasty & \\
$\quad$ Rigid, complete ring & $56(29.0)$ \\
Semirigid, complete ring & $76(39.4)$ \\
Flexible, complete ring & $12(6.2)$ \\
Flexible, partial ring & $12(6.2)$ \\
Sliding annuloplasty & $3(1.6)$ \\
Leaflet repair & \\
Commissurotomy or leaflet mobilization & $139(72.0)$ \\
Leaflet extension or augmentation & $18(9.3)$ \\
Triangular or quadrangular resection & $9(4.7)$ \\
Subvalvular apparatus repair & \\
Chordae & \\
$\quad$ Fenestration & \\
Shortening & $1(0.5)$ \\
Transfer & $1(0.5)$ \\
Transposition & $5(2.6)$ \\
New chordate formation & $2(1.0)$ \\
$\quad$ Resection & $58(30.1)$ \\
Tricuspillary muscle splitting & $16(8.3)$ \\
Ring annulve repair & $66(34.2)$ \\
Suture annuloplasty & \\
\hline & $39(20.2)$ \\
& $29(15.0)$ \\
\hline
\end{tabular}

survival at 5 years and 10 years was $96.7 \% \pm 1.3 \%$ and $92.2 \% \pm 2.6 \%$, respectively. During the follow-up period, there were 10 valve-related events, including thromboembolic events in 3 patients, MV reoperation in 5 patients, and bleeding complications secondary to anticoagulation in 2 patients. All the reoperations were MV replacements. All the thromboembolic events were cerebrovascular accidents that occurred after $>1$ year. There were no cases of infective endocarditis. The 5- and 10-year freedom from reoperation rate was $97.5 \% \pm 1.2 \%$ and $96.7 \% \pm 1.5 \%$, respectively (Figure 1). Overall valve-related, event-free survival at 5 years and 10 years was $90.3 \% \pm 2.3 \%$ and $85.5 \% \pm 3.3 \%$, respectively. These event-free survival rates were influenced negatively by postoperative late $\mathrm{AF}$ $(P=.009$, Figure 2$)$. In the Cox proportional hazards model, postoperative late AF was the only independent predictor of decreased event-free survival (HR, 3.18; 95\% CI, $1.27-7.67 ; P=.014)$. The 10 -year freedom from late $\mathrm{AF}$ was $95.9 \%, 77.0 \%$, and $27.3 \%$ in normal sinus rhythm at preoperative state, Maze for AF, and non-Maze for AF, respectively $(P<.001$, Figure 3$)$.

\section{Mitral Valve Dysfunctions}

One hundred seventy-three patients $(89.6 \%)$ were evaluated with echocardiography for $>6$ months postoperatively.
TABLE 2. Baseline characteristics of all patients

\begin{tabular}{lc}
\hline \multicolumn{1}{c}{ Characteristic } & No. of cases $(\%)$ or mean \pm SD \\
\hline No. of patients & 193 \\
Age, years & $39.4 \pm 12.8$ \\
Female gender, \% & $154(79.8)$ \\
NYHA functional class & \\
I & $1(0.5)$ \\
II & $110(57.0)$ \\
III & $70(36.3)$ \\
IV & $11(5.7)$ \\
Diabetes mellitus & $5(2.6)$ \\
Hypertension & $7(3.6)$ \\
One-vessel coronary disease & $3(1.6)$ \\
Atrial fibrillation & $113(58.5)$ \\
Maze procedure* & $102(90.3)$ \\
Diagnosis of MV disease & \\
Predominant MS & $16(8.3)$ \\
Predominant MR & $146(75.6)$ \\
Mixed MSR & $31(16.1)$ \\
Echocardiographic data & \\
Left atrial size, mm & $57.5 \pm 10.1$ \\
LV end-systolic dimension, mm & $41.1 \pm 7.2$ \\
LV end-diastolic dimension, mm & $60.6 \pm 9.0$ \\
LV ejection fraction, \% & $57.7 \pm 9.8$ \\
Tricuspid regurgitation $>$ grade 2 & $45(23.3)$ \\
Significant pulmonary hypertension & $15(7.8)$ \\
\hline$D$ S &
\end{tabular}

$S D$, Standard deviations; NYHA, New York Heart Association; $M V$, mitral valve; $M S$, mitral stenosis; $M R$, mitral regurgitation; $M S R$, Mitral stenoregurgitation; $L V$, left ventricle. *The number of patients with atrial fibrillation.

During a mean echocardiography follow-up duration of $53.7 \pm 43.5$ months, 40 patients $(16.7 \%)$ showed either significant mitral regurgitation ( $>$ mild; $\mathrm{n}=31$ ) or significant mitral stenosis (MV area, $\leq 1.5 \mathrm{~cm}^{2} ; \mathrm{n}=9$ ). No patient showed a significant mixed mitral stenoregurgitation pattern. Freedom from moderate to severe MV dysfunctions at 5 years and 10 years was $83.2 \% \pm 3.2 \%$ and $66.4 \% \pm$ $5.4 \%$, respectively. Significant mitral dysfunctions were found more frequently in patients who did not undergo a Maze procedure in the presence of AF than in those who were subjected to a concomitant Maze procedure $(P=.014$, Figure 4). Cox multivariate analysis revealed that no Maze operation for $\mathrm{AF}$ was an independent predictor of mitral dysfunctions (HR, 3.72; 95\% CI, 1.47-9.42; $P=.005$ ), whereas the presence of hypertension had borderline significance (HR, 3.15; 95\% CI, 0.96-10.38; $P=.059$; Table 3). Postoperative mitral dysfunctions according to rhythm status and combination of the Maze procedure are shown in Table 4.

\section{DISCUSSION}

This study demonstrated that valve repair for rheumatic mitral disease provided excellent long-term clinical outcomes with regard to overall survival and valve-related, event-free survival. However, a significant proportion of 

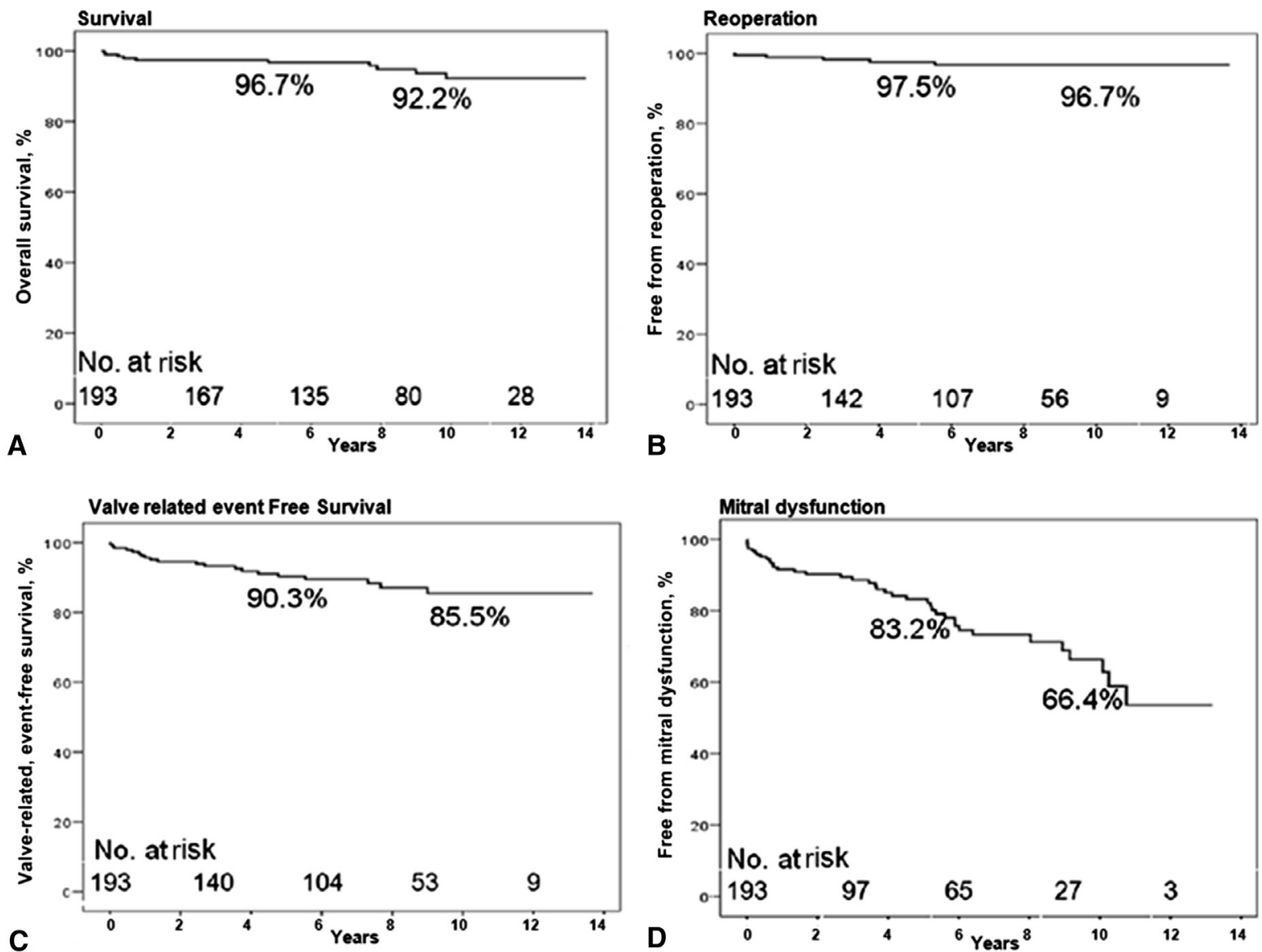

FIGURE 1. Kaplan-Meier curves of long-term outcomes for patients who were subjected to rheumatic mitral repair. (A) Overall survival. (B) Freedom from reoperation. (C) Valve-related event-free survival. (D) Freedom from mitral dysfunctions.

patients experienced moderate to severe MV dysfunctions postoperatively. In multivariate analysis, both the presence of hypertension and a lack of a Maze operation for AF were

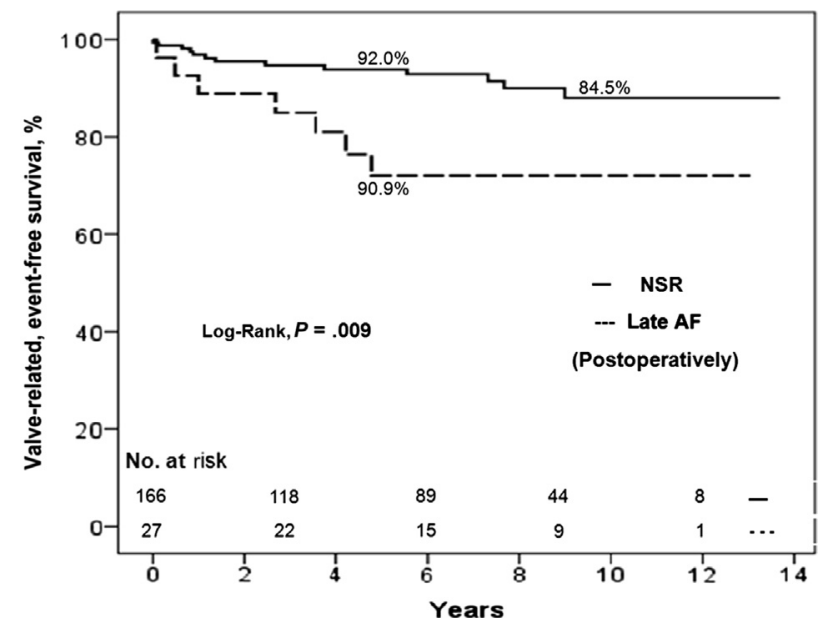

FIGURE 2. Kaplan-Meier curves for valve-related, event-free survival based on the presence of late atrial fibrillation postoperatively. NSR, Normal sinus rhythm; $A F$, atrial fibrillation. independent factors associated with increased MV dysfunctions.

The better choice of valve procedure (repair vs replacement) for long-term durability in patients with rheumatic mitral disease remains questionable. Previous studies showed that $82 \%$ to $92 \%$ of patients did not require a reoperation by 10 years after the initial procedure. ${ }^{8,14,18}$ Results of the current study (a 10-year freedom-from-reoperation rate of $97 \%$ ) corresponded with those of previous studies and suggest an acceptable reoperation rate.

As for durability after rheumatic mitral repair, most previous studies focused on reoperation rate and did not consider postoperative mitral dysfunctions. ${ }^{7,8}$ However, the current study detected that a significant number of patients subjected to rheumatic mitral repair experienced postoperative MV dysfunction despite the acceptable reoperation rate. The rates of freedom from reoperation and freedom from moderate to severe mitral dysfunctions at 10 years were $97 \%$ and $66 \%$, respectively, showing a significant gap between the numbers. Although analysis based on reoperation rate is limited for evaluating actual durability of the MV after repair, analysis that considers mitral dysfunctions may 


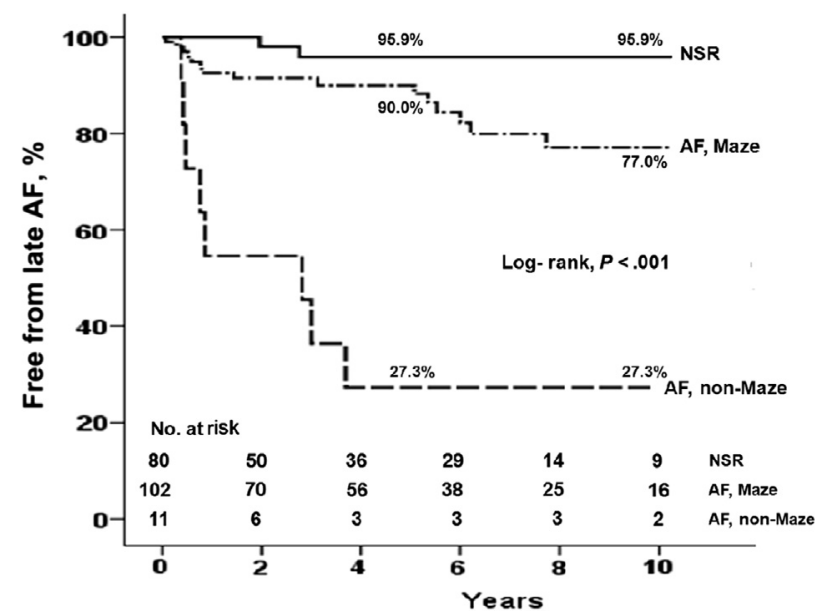

FIGURE 3. Kaplan-Meier curves for freedom from late atrial fibrillation based on rhythm status and combination of the Maze procedure (non-Maze for AF vs Maze for AF vs NSR). NSR, Normal sinus rhythm at preoperative state; $A F$, atrial fibrillation.

provide more information and understanding about durability.

The current study found that both the presence of hypertension and the lack of a Maze operation for AF were independent factors associated with postoperative mitral dysfunction. This study found a hazard ratio of 3.15 $(P=.059)$ for postoperative MV dysfunctions in patients with hypertension. Although the precise mechanisms of how hypertension affects postoperative mitral dysfunctions are unknown, there are some data that suggest detrimental effects of hypertension on the MV. ${ }^{19,20}$ Hypertension

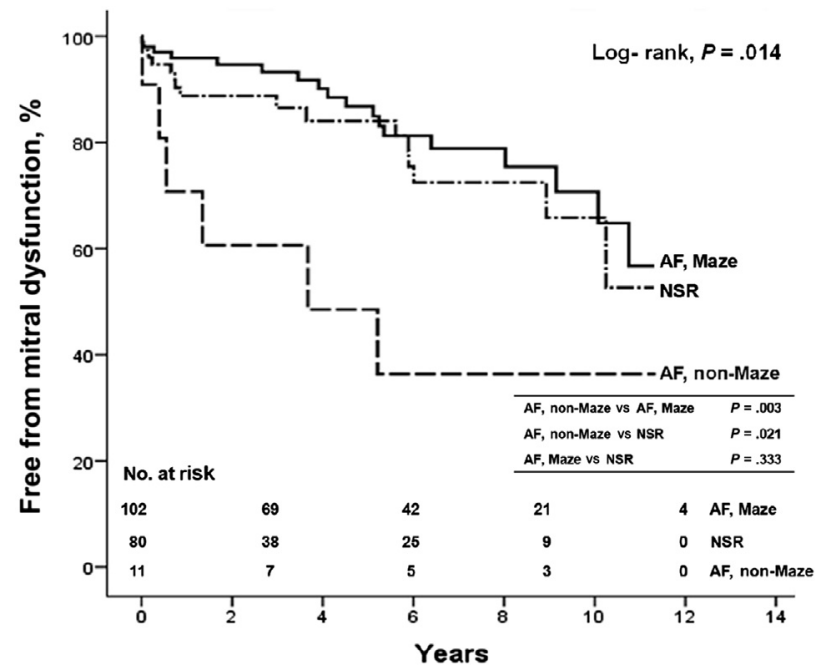

FIGURE 4. Kaplan-Meier curves for freedom from mitral dysfunctions based on rhythm status and combination of the Maze procedure (nonMaze for AF vs Maze for AF vs NSR). AF, Atrial fibrillation; NSR, normal sinus rhythm at preoperative state.
TABLE 3. Univariate and multivariate analyses of mitral valve dysfunctions

\begin{tabular}{|c|c|c|c|}
\hline & \multirow{2}{*}{$\begin{array}{c}\text { Univariate } \\
P \\
\text { value }\end{array}$} & \multicolumn{2}{|l|}{ Multivariate } \\
\hline & & $\begin{array}{c}\text { Hazard } \\
\text { ratio }(95 \% \mathrm{CI})\end{array}$ & $\begin{array}{c}P \\
\text { value }\end{array}$ \\
\hline \multicolumn{4}{|l|}{ Preoperative factors } \\
\hline Age & .685 & & \\
\hline Female gender & .792 & & \\
\hline NYHA functional class $>2$ & .644 & & \\
\hline Diabetes mellitus & .548 & & \\
\hline Hypertension & $.066^{*}$ & $3.15(0.96-10.38)$ & $.059 *$ \\
\hline One-vessel coronary disease & .630 & & \\
\hline Type of mitral valve pathology & 677 & & \\
\hline Preoperative atrial fibrillation & .716 & & \\
\hline \multicolumn{4}{|l|}{ Operative factors } \\
\hline Minimally invasive approach & .371 & & \\
\hline Mitral ring annuloplasty & .850 & & \\
\hline Tricuspid annuloplasty & .550 & & \\
\hline $\begin{array}{l}\text { No Maze procedure for } \mathrm{AF} \text { vs } \\
\text { Maze procedure for } \mathrm{AF}\end{array}$ & $.006 *$ & $3.72(1.47-9.42)$ & $.005 *$ \\
\hline Maze energy source & .446 & & \\
\hline \multicolumn{4}{|l|}{ Preoperative echocardiographic data } \\
\hline Left atrial size $>60 \mathrm{~mm}$ & .905 & & \\
\hline $\begin{array}{l}\mathrm{LV} \text { end-systolic dimension } \\
\quad>40 \mathrm{~mm}\end{array}$ & .227 & & \\
\hline $\begin{array}{l}\text { LV end-diastolic dimension } \\
\quad>60 \mathrm{~mm}\end{array}$ & .387 & & \\
\hline LV ejection fraction, $\%$ & .758 & & \\
\hline $\begin{array}{l}\text { Tricuspid regurgitation } \\
>\text { grade } 2\end{array}$ & .617 & & \\
\hline $\begin{array}{l}\text { Significant pulmonary } \\
\text { hypertension }\end{array}$ & .174 & & \\
\hline
\end{tabular}

$L V$, left ventricle. $* P<.05$.

interferes with atrioventricular reverse remodeling after mitral repair and can lead to abnormal changes in geometry such as less left atrium volume regression and left ventricular mass regression. ${ }^{21}$ Our findings may help to uncover the roles of hypertension on the MV.

In this study, another interesting finding was that a lack of the Maze operation for AF was a risk factor for increased MV dysfunction. A previous study suggested that postoperative MV dysfunctions could affect late recurrence of $\mathrm{AF}^{22}$ However, our findings provide another viewpoint on the

TABLE 4. Postoperative mitral dysfunction according to rhythm status and combination of the Maze procedure

\begin{tabular}{|c|c|c|c|c|}
\hline & $\begin{array}{c}\text { NSR } \\
(\mathbf{n}=\mathbf{8 0})\end{array}$ & $\begin{array}{l}\text { AF, Maze } \\
(n=102)\end{array}$ & $\begin{array}{l}\text { AF, non-Maze } \\
\quad(\mathbf{n}=\mathbf{1 1})\end{array}$ & $\begin{array}{c}P \\
\text { value }\end{array}$ \\
\hline Mitral regurgitation $(>$ mild $)$ & 12 & 14 & 5 & .040 \\
\hline $\begin{array}{l}\text { Mitral stenosis (MVA of } \\
\leq 1.5 \mathrm{~cm}^{2} \text { ) }\end{array}$ & 4 & 4 & 1 & .505 \\
\hline Mitral dysfunctions & 16 & 18 & 6 & .023 \\
\hline
\end{tabular}


relationship between AF and postoperative MV function. The rhythm status of the heart can be affected by the function of the MV and vice versa. After surgical intervention, patients with persistent AF remain at risk for asynchronous atrioventricular contraction. The absence of an atrial kick may prevent normal atrial remodeling and may compromise the efficacy of MV repair. ${ }^{23}$ Pai and colleagues ${ }^{24}$ analyzed echocardiographic data for 62 patients with either $\mathrm{AF}(\mathrm{n}=25)$ or normal sinus rhythm $(\mathrm{n}=37)$ in 2003. They concluded that AF blunts or eliminates the phasic changes in mitral annular size during the cardiac cycle, and this may have implications for the genesis and surgical correction of mitral regurgitations. ${ }^{24}$ Heart rhythm status is reported to contribute to maintenance of MV function. In a study involving 73 patients with persistent AF, echocardiographic assessments were performed both before and after successful electrical cardioversions of $\mathrm{AF}^{25}$ In that study, the restoration of the sinus rhythm resulted in a significant reduction in MR jet area. In another recent study assessing MV function before and after $\mathrm{AF}$ ablation, restoration of synchronous atrioventricular contraction contributed to a reduction in functional compartment of mitral regurgitation. ${ }^{26}$ These phenomena can be explained by an underlying mechanism that dilatation of the mitral annulus secondary to AF predisposes to mitral regurgitation. ${ }^{27}$ Therefore, normalization of heart rhythm by the Maze operation for AF may be also important in the maintenance of MV function following the surgical repair of rheumatic MV disease. Based on our findings, we believe that a concomitant Maze operation should always be performed in patients with $\mathrm{AF}$ at the time of mitral repair. This is important not only for cardiac rhythm correction, but also for the competence of MV function.

\section{Limitations}

This study was subjected to the limitations inherent in a retrospective study using observational data of a single center. Another limitation is that late ( $>6$ months) postoperative echocardiographic data were not available in $10.4 \%$ of patients. Last, although lack of the Maze operation for AF was associated strongly with postoperative mitral dysfunctions, the number of patients who had not undergone the Maze operation in the presence of $\mathrm{AF}$ was too small to draw a strong conclusion.

\section{CONCLUSIONS}

Despite excellent long-term clinical outcomes of rheumatic mitral repair, a significant number of patients experienced mitral dysfunctions postoperatively. Uncorrected AF without a concomitant Maze procedure increased significantly the risks of mitral dysfunction and adverse outcomes. Therefore, in the presence of AF, a concomitant Maze procedure is suggested whenever possible.

\section{References}

1. Yankah CA, Siniawski H, Detschades C, Stein J, Hetzer R. Rheumatic mitral valve repair: 22-year clinical results. J Heart Valve Dis. 2011;20:257-64.

2. Carpentier A. Cardiac valve surgery: the "French correction" J Thorac Cardiovasc Surg. 1983;86:323-7.

3. Duran CM, Gometza B, Saad E. Valve repair in rheumatic mitral disease: an unsolved problem. J Card Surg. 1994;9:282-5.

4. David TE, Uden DE, Strauss HD. The importance of the mitral apparatus in left ventricular function after correction of mitral regurgitation. Circulation. 1983; 68:76-82.

5. Oumeiri BE, Boodhwani M, Glineur D, Kerchove LD, Poncelet A, Astarci P, et al. Extending the scope of mitral valve repair in rheumatic disease. Ann Thorac Surg. 2009;87:1735-40.

6. Suri RM, Schaff HV, Dearani JA, Sundt TM, Daly RC, Mullany CJ, et al. Survival advantage and improved durability of mitral repair for leaflet prolapsed subsets in the current era. Ann Thorac Surg. 2006;82:819-27.

7. DiBardino DJ, ElBardissi AW, McClure RS, Razo-Vasquez OA, Kelly NE, Cohn LH. Four decades of experience with mitral valve repair: analysis of differential indications, technical evolution, and long-term outcome. J Thorac Cardiovasc Surg. 2010;139:76-83.

8. Chauvaud S, Fuzellier JF, Berrebi A, Deloche A, Fabiani JN, Carpentier A. Long-term (29 years) results of reconstructive surgery in rheumatic mitral valve insufficiency. Circulation. 2001;104:12-5.

9. Kim JB, Kim HJ, Moon DH, Jung SH, Choo SJ, Chung CH, et al. Longterm outcomes after surgery for rheumatic mitral valve disease: valve repair versus mechanical valve replacement. Eur J Cardiothorac Surg. 2010;37: 1039-46.

10. Yau TM, Farag El-Ghoneimi YA, Armstrong S, Ivanov J, David TE. Mitral valve repair and replacement for rheumatic disease. J Thorac Cardiovasc Surg. 2000; 119:53-61.

11. Daneshmand MA, Milano CA, Rankin JS, Honeycutt EF, Swaninathan M, Shaw LK, et al. Mitral valve repair for degenerative disease: a 20-year experience. Ann Thorac Surg. 2009;88:1828-37.

12. Gillinov AM, Cosgrove DM, Blackstone EH, Diaz R, Arnold JH, Lytle BW, et al. Durability of mitral valve repair for degenerative disease. $J$ Thorac Cardiovasc Surg. 1998;116:734-43.

13. Shuhaiber J, Anderson RJ. Meta-analysis of clinical outcomes following surgical mitral valve repair or replacement. Eur J Cardiothorac Surg. 2007;31: 267-75.

14. Mohty D, Orszulak TA, Schaff HV, Avierinos JF, Tajik JA, Enriquez-Sarano M. Very long-term survival and durability of mitral valve repair for mitral valve prolapse. Circulation. 2001;104:1-7.

15. Lee JW, Choo SJ, Kim KI, Song JK, Kang DH, Song JM, et al. Atrial fibrillation surgery simplified with cryoablation to improve left atrial function. Ann Thorac Surg. 2001;72:1479-83.

16. Kim JB, Bang JH, Jung SH, Choo SJ, Chung CH, Lee JW. Left atrial ablation versus biatrial ablation in the surgical treatment of atrial fibrillation. Ann Thorac Surg. 2011;92:1397-404

17. Akins CW, Miller C, Turina MI, Kouchoukos NT, Blackstone EH, Grunkemeier GL, et al. Guidelines for reporting mortality and morbidity after cardiac valve interventions. Ann Thorac Surg. 2008;85:1490-5.

18. Talwar S, Rajesh MR, Subramanian A, Saxena A, Kumar AS. Mitral valve repair in children with rheumatic heart disease. J Thorac Cardiovasc Surg. 2005;129: 875-9.

19. Aslam F, Haque A, Foody J, Shirani J. The frequency and functional impact of overlapping hypertension on hypertrophic cardiomyopathy: a single-center experience. J Clin Hypertens (Greenwich). 2010;12:240-5.

20. Facchin L, Nordio M, Levedianos G, Dilanas C, Marchini P, Leprotti C, et al. Role of hypertension in determining valvular diseases in patients with chronic uremia and dialytic treatment. Cardiologia. 1988;43:1361-6.

21. Brandt MC, Mahfoud F, Reda S, Schirmer SH, Erdmann E, Bohm M, et al. Renal sympathetic denervation reduces left ventricular hypertrophy and improves cardiac function in patients with resistant hypertension. J Am Coll Cardiol. 2012;59: 901-9.

22. Kim JB, Lee SH, Jung SH, Yun SC, Choo SJ, Chung CH, et al. The influence of postoperative mitral valve function on the late recurrence of atrial fibrillation after the Maze procedure combined with mitral valvuloplasty. J Thorac Cardiovasc Surg. 2010;139:1170-6.

23. Voeller RK, Schuessler RB, Damiano RJ. Surgical treatment of atrial fibrillation. In: Cohn LH, ed. Cardiac surgery in the adult. 3rd ed. New York: McGraw-Hill; 2008:1251-76. 
24. Pai RG, Varadarajan P, Tanimoto M. Effect of atrial fibrillation on the dynamics of mitral annular area. J Heart Valve Dis. 2003;12:31-7.

25. Dell'Era G, Rondano E, Franchi E, Marino PN, Novara atrial fibrillation (NAIF) study group. Atrial asynchrony and function before and after electrical cardioversion for persistent atrial fibrillation. Eur J Echocardiogr. 2010;11: 577-83.
26. Gertz ZM, Raina A, Saghy L, Zado ES, Callans DJ, Marchlinski FE, et al. Evidence of atrial functional mitral regurgitation due to atrial fibrillation: reversal with arrhythmia control. J Am Coll Cardiol. 2011;58:1474-81.

27. Vohra HA, Whistance RN, Magan A, Sadeque SA, Livesey SA. Mitral valve repair for severe mitral regurgitation secondary to lone atrial fibrillation. Eur J Cardiothorac Surg. February 8, 2012 [Epub ahead of print] 